\title{
Tracing Metabolic Changes in Soybean Cotyledons during Germination by NMR
}

\author{
Nobuaki Ishida, ${ }^{*}$ Toshio Kobayashi, ${ }^{*}$ Ryoichi Masuda, ${ }^{*}$ \\ Hiromi KanO, ${ }^{* *}$ Takashi YoshidA*** and Hidejiro OGAWA**** \\ * National Food Research Institute, Tsukuba Science City, \\ Ibaraki 305, Japan \\ **National Institute of Agrobiological Resources, \\ Tsukuba Science City, Ibaraki 305, Japan \\ *** National Institute of Vegetables, Ornamental Crops, and Tea, \\ Kusawa, Ano, Mie 514-23, Japan \\ ****JEOL Ltd., Musashino. Akishima, Tokyo 196. Japan \\ Received October 25, 1989
}

\begin{abstract}
The changes in ${ }^{13} \mathrm{C}-\mathrm{NMR}$ and ${ }^{31} \mathrm{P}-\mathrm{N} M R$ spectra and ${ }^{1} \mathrm{H}-\mathrm{NMR}$ images in soybean cotyledons during germination were investigated. Using ${ }^{13} \mathrm{C}-\mathrm{NMR}$, fatty acid signals in the form of triglycerides were observed in dry seeds, and those were observed approximately 18 days after the start of imbibition. Sucrose signals appeared at $16 \mathrm{hr}$ and disappeared at 5 days. $\mathrm{A}-\stackrel{+}{\mathrm{N}}-\left(\mathrm{CH}_{3}\right)_{3}$ signal was observed after 5 days, suggesting the activation of membrane metabolism in the cotyledons.

${ }^{31} \mathrm{P}-\mathrm{NMR}$ signals appeared $2 \mathrm{hr}$ after imbibition before any apparent change in the ${ }^{13} \mathrm{C}-\mathrm{NMR}$ spectrum. The peaks identified as sugar phosphate, inorganic phosphate in the cytoplasm and in the vacuole, and an unassigned compound, were distinguishable after 5 days. The vacuole-associated inorganic phosphate peak became prominent 18 days after imbibition in ${ }^{31} \mathrm{P}-\mathrm{NMR}$.

Distribution maps of free water indicated that the stored macro-molecular materials which bound water were consumed heterogeneously within the cotyledon. The relaxation time $\left(T_{1}\right)$ increased suddenly between 18 days and 23 days after imbibition, which indicates the consumption of stored materials.

These findings suggest that cotyledons are the source of such compounds and the energy required for plant growth for approximately 18 days from germination until tri-foliolate leaves begin developing.
\end{abstract}

Soybean cotyledons are the primary source of the energy and the compounds required for organizing plant systems during the initial growth stages following germination. ${ }^{1)}$ The conditions and the properties of cotyledons directly influence the growth of seedlings afterward. Seeds initiate the cellular metabolism associated with the accumulation of metabolites and the release of energy at the imbibition of water. ${ }^{2)}$ Stored materials are consumed and the accompanying changes of water condition in cotyledon cells are anticipated along with the progression of growth stages. This process was traced using ${ }^{13} \mathrm{C}-\mathrm{NMR},{ }^{31} \mathrm{P}$ NMR, and ${ }^{1} \mathrm{H}-\mathrm{NMR}$, which are well-known techniques of in vivo measurement, ${ }^{3,4)}$ to elu- cidate how long cotyledons sustain plant growth. ${ }^{1} \mathrm{H}-\mathrm{NMR}$ imaging was used because of its usefulness in tracing the dynamic changes of water conditions in relation to the morphological aspect of plant tissues. ${ }^{5,6)}$

\section{Materials and Methods}

Plants. Soybean (Glycine max cv. Enrei) seeds-were let imbibe and germinated on wet paper at $25^{\circ} \mathrm{C}$ in a dark room, and transferred to hydrophonic culture systems. Culture medium containing $1 / 10$ strength Hoagland solution $^{7 /}$ was supplied. Plants were grown at $25^{\circ} \mathrm{C}$ in the daytime and $20^{\circ} \mathrm{C}$ at night under artificial light at approximately 10,000 lux. Cotyledons of seedlings were excised and put into the sample tube of a high resolution NMR or a sample holder of an ${ }^{1} \mathrm{H}-\mathrm{NMR}$ imaging apparatus for 
non-destructive measurements.

Measurement of NMR spectra. High resolution NMR spectra were measured using a JEOL FX $100(100 \mathrm{MHz}$ for ${ }^{1} \mathrm{H}$ ) spectrometer with a resistive magnet using an external lock system $\left(D_{2}\right){ }^{8}$ ) The diameter of the sample tube was $10 \mathrm{~mm}$ and the soybean cotyledon was placed in it without treatment. ${ }^{13} \mathrm{C}$ - and ${ }^{31} \mathrm{P}$-NMR spectra were measured under completely proton decoupling conditions. The pulse angle was $45^{\circ}$ and the repetition times was 1.0 sec for ${ }^{13} \mathrm{C}-\mathrm{NMR}$ and $1.5 \mathrm{sec}$ for ${ }^{31} \mathrm{P}$-NMR measurement.

Twelve-day-old soybean cotyledons were homogenized in distilled water by adjusting the $\mathrm{pH}$ to approximately 7.0 and centrifuged at $10,000 \times g$ for $5 \mathrm{~min}$. The supernatant was defatted by $\mathrm{CHCl}_{3}, \mathrm{EtOH}$ was added to $80 \%$ $(\mathrm{v} / \mathrm{v})$, and the solution was centrifuged to remove proteins, concentrated in vacuo, and treated with CHELEX-100 to remove divalent cations. ${ }^{31} \mathrm{P}-\mathrm{NMR}$ spectra were measured after addition of EDTA under completely proton decoupling conditions. A pulse angle of $60^{\circ}$ was used and the repetition time was $5.0 \mathrm{sec}$.

A JEOL GSX-270 NMR-spectrometer with a superconducting magnet operating at $270 \mathrm{MHz}$ was used for obtaining ${ }^{1} \mathrm{H}$-NMR images. ') An intact soybean cotyledon was fixed on a sample holder and inserted into the magnet which was equipped with a gradient coil $(15 \mathrm{mT} / \mathrm{m})$ for the magnetic field of the apparatus. A spin-echo two dimensional FT method was used to make the images. The delay time between excitation and acquisition of the spinecho signal was $36 \mathrm{msec}$. The images were created with a resolution of $0.2 \mathrm{~mm} \times 0.2 \mathrm{~mm}$ and a $1.0 \mathrm{~mm}$ slice thickness $\left(0.04 \mathrm{~mm}^{3}\right)$. Three imaging pulse sequences with different repetition times $(0.5,1.5$ and $5.0 \mathrm{sec})$ were used to measure the average relaxation times $\left(T_{1}\right)$ of water by the progressive saturation method.

\section{Results and Discussion}

Soybean seeds that had imbibed water germinated on the second or third day. They were transplanted on the 5 th or 6th day when the total length of hypocotyl and radicle reached $5 \mathrm{~cm}$. The primary leaves were fully developed within 3 weeks. The materials required for plant growth are primarily supplied by the cotyledons during these growth processes. Stored materials such as saccharides, proteins, and fatty acids in the cotyledon are degradated to low molecular weight compounds, which are transported and consumed by the plant. ${ }^{1,2}$

The signals of fatty acids, stored as triglycerides, were observed in the ${ }^{13} \mathrm{C}$-NMR spectrum, ${ }^{10)}$ but no ${ }^{31} \mathrm{P}-\mathrm{NMR}$ signal was observed ${ }^{8)}$ in the dry seed. The change in the ${ }^{13} \mathrm{C}$ -

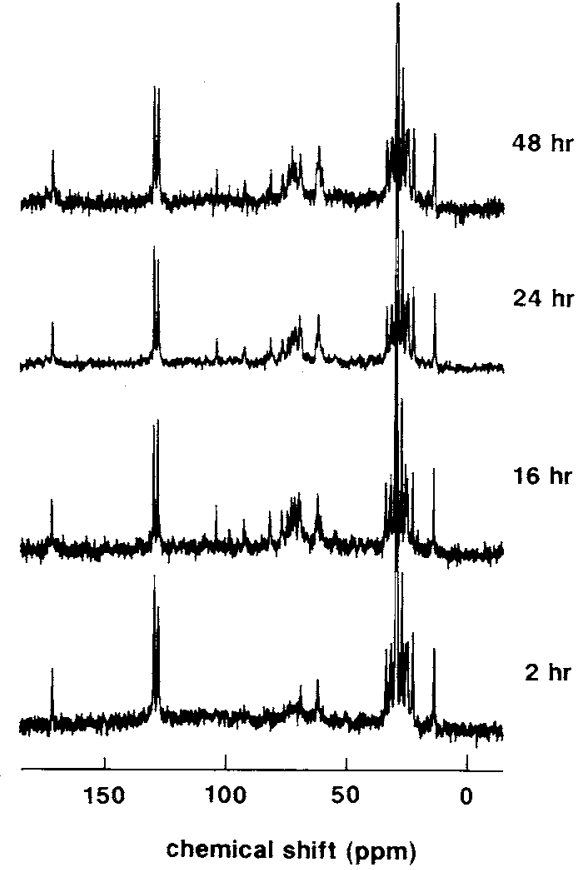

(a)

18 days

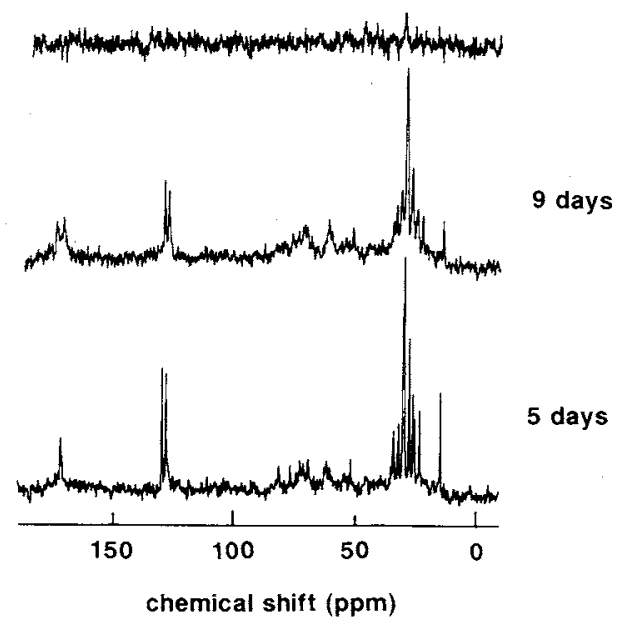

(b)

Fig. 1. ${ }^{13}$ C-NMR Spectra at Various Stages of Germination from 2 to $48 \mathrm{hr}$ (a) and from 5 to 18 Days (b).

The scale is in ppm downfield from tetramethylsilane (TMS).

NMR spectrum of the cotyledon ${ }^{11)}$ is shown in Fig. la and $b$ along with the progression of the growth stages of seedlings. The cotyledon $2 \mathrm{hr}$ after imbibition also showed the signals of 
triglyceride-fatty-acid. The signal at $14 \mathrm{ppm}$ was ascribed to a methyl group, those around $30 \mathrm{ppm}$ to methylene clusters, two signals at $62 \mathrm{ppm}$ and $70 \mathrm{ppm}$ to glycerol, signals around $130 \mathrm{ppm}$ to a double bond and at $172 \mathrm{ppm}$ to fatty acid carbonyl. The signals ascribed to sucrose (from $60 \mathrm{ppm}$ to $110 \mathrm{ppm}$ ) appeared at $16 \mathrm{hr}$, decreased at 5 days, and diminished 9 days after imbibition. In 5-day-old cotyledons, sugar signals (around $100 \mathrm{ppm}$ ) other than sucrose and a $\mathrm{N}^{+}$-methyl carbon signal that was

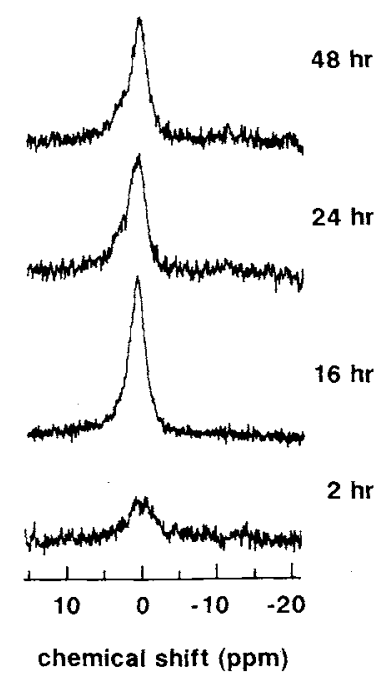

(a)

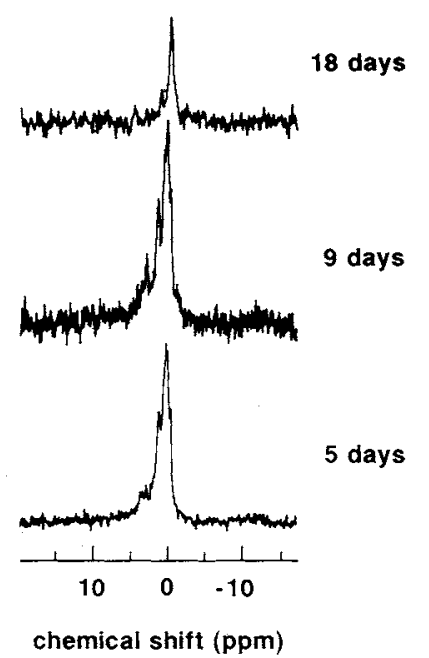

(b)

Fig. 2. ${ }^{31} \mathrm{P}-\mathrm{NMR}$ Spectra at Various Stages of Germination from 2 to $48 \mathrm{hr}$ (a) and from 5 to 18 Days (b). The scale is in ppm from inorganic phosphate $(85 \%)$. ascribed to cholin ${ }^{12)}(55 \mathrm{ppm})$ were observed. At 9 days, the carbonyl signal of organic acids at $180 \mathrm{ppm}$ was observed as well as the signals of fatty acids and the $-\stackrel{+}{\mathrm{N}}-\left(\mathrm{CH}_{3}\right)_{3}$ signal. The signals of fatty acids and the other compounds decreased until the 11 th day.

The ${ }^{31} \mathrm{P}-\mathrm{NMR}$ spectrum (Fig. 2a) showed a broad inorganic phosphate peak after $2 \mathrm{hr}$ of imbibition, suggesting that the cotyledon was already in an active state though no change was detectable in the ${ }^{13} \mathrm{C}-\mathrm{NMR}$ spectrum. The inorganic phosphate increased and a shoulder due to sugar phosphate peaks became apparent after $16 \mathrm{hr}$. Sugar phosphate peaks from 3 to $4 \mathrm{ppm}$, inorganic phosphate in cytoplasm at $1.45 \mathrm{ppm}$, inorganic phosphate in vacuoles at $0.58 \mathrm{ppm}$, and an unassigned compound at $-0.05 \mathrm{ppm}$ were distinguished after 5 days (Fig. 2b). The amount of sugar phos-

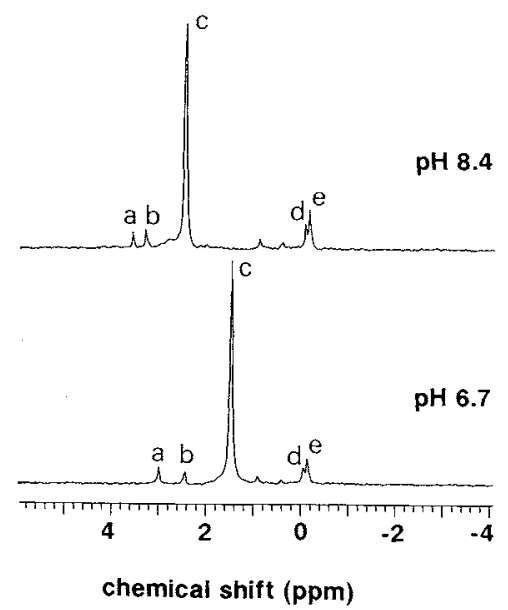

Fig. 3. ${ }^{31} \mathrm{P}-\mathrm{NMR}$ Spectra of Water Extracts of 12-dayold Soybean Cotyledons at $\mathrm{pH} 6.7$ and $\mathrm{pH} 8.4$.

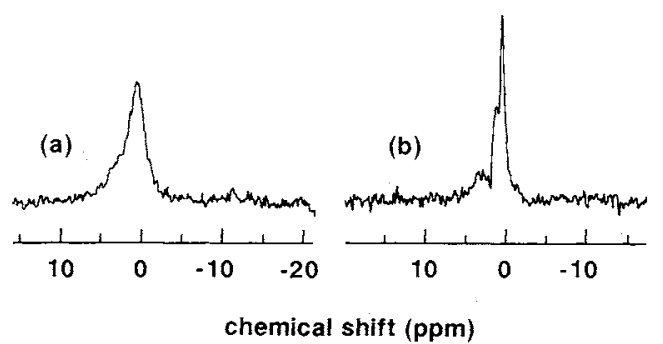

Fig. 4. Comparison of ${ }^{31} \mathrm{P}-\mathrm{NMR}$ Spectrum of Soybean Cotyledons Containing $60 \%$ Water during Germination (a) with That Containing $63 \%$ Water during Maturation (b). 
phate, inorganic phosphate in cytoplasm, and unassigned compound greatly decreased between 9 days and 18 days and only the peak of inorganic phosphate in the vacuole became prominent.

Figure 3 shows the ${ }^{31} \mathrm{P}-\mathrm{NMR}$ spectra of water extracts of soybean cotyledons 12 days after imbibition at $\mathrm{pH} 6.7$ and 8.4 . Of the major peaks observed (a,b,c,d, and e), the chemical shifts of peaks $a, b$, and $c$ were changed by the alternation of the medium $\mathrm{pH}$ from 6.7 to 8.4. Based on these chemical shift changes, peaks $a, b$, and $c$ were identified as glucose-6-phosphate, fructose-6-phosphate, and inorganic phosphate, respectively. Peaks d and $\mathrm{e}$ around $0 \mathrm{ppm}$ were not affected by medium $\mathrm{pH}$; they were thought to be phospholipid from the results of thin layer chromatography (data not shown). Accumulation of phospholipids in ${ }^{31} \mathrm{P}-\mathrm{NMR}$ together with the appearance of the $-\hat{N}-\left(\mathrm{CH}_{3}\right)_{3}$ signal suggest the activation of membrane metabolism.

${ }^{31} \mathrm{P}-\mathrm{NMR}$ spectra taken during germination and maturation of seeds which contained approximately $60 \%$ water are compared in Fig. 4. Peaks from sugar phosphate and inorganic phosphate in cytoplasm and vacuoles were distinguishable during maturation, while a broad asymmetric peak was observed during germination. This suggests a difference in the mobility of phosphates resulted from different physical and chemical conditions in the two cotyledons. Broadening of the signal was as- cribed to the binding of water by macromolecules that resulted in the decline of the mobility of solubilized phosphorus compounds and to the interaction of phosphates with divalent cations in the cells. Materials flowing into the seed are accumulated in the proper places and converted to solids by a tightly organized system in the cotyledon in the course of maturation, therefore, the cytoplasmic and the vacuolar water would be maintained in highly mobile states until the water content went down to $30 \%{ }^{8}{ }^{8}$ On the other hand, accumulated materials are solubilized before the re-organization of membranes and the reactivation of their function at imbibition, therefore, excess compounds were released into the cytoplasm, broadening the peaks by binding water with macromolecular compounds and by the interaction of phosphates with high concentration of divalent cations. The recovery of cell membrane organization and function in the cotyledon was considered to be finished by the 5th day after imbibition (Fig. 2b), based on the fact that the ordinary split of the peak was observed from the narrowing of the line width of the signals.

Highly mobile free water is considered to be the primary field where biological reactions in the cells occur. ${ }^{1} \mathrm{H}-\mathrm{NMR}$ images corresponding to the distribution map of free water were observed along with the progression of growth. Images of sliced sections of the cotyledon 18 days after imbibition are shown in
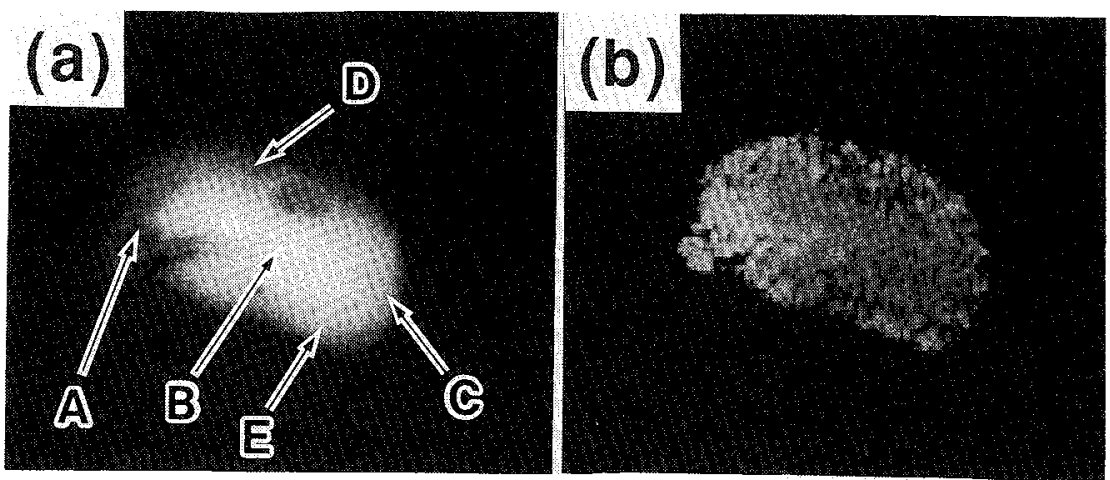

Fig. 5. Distribution Maps of Free Water in Cotyledon with Structural Image (a), and Maps of Relaxation Times $\left(T_{1}\right)($ b) 18 days after Imbibition.

The symbols A, B, C, D, and E indicate the sampling points in Fig. 6 and Table I. 
Fig. 5a. Non-uniform distribution of the free water was observed. The top (C) and middle (B) parts of the cotyledon contained larger amounts of free water while free water in the base (A) was less. The spin-lattice relaxation times $\left(T_{1}\right)$ of free water were measured by the progressive saturation method. Using the three water distribution maps measured by pulse sequence with different repetition times, relaxation times were calculated as shown in Fig. 6, and the image map of the relaxation time is shown in Fig. 5b. The values of $T_{1}$ indicated are the averaged values of various types of water. Water in the base and the edges of the cotyledon showed longer relaxa-

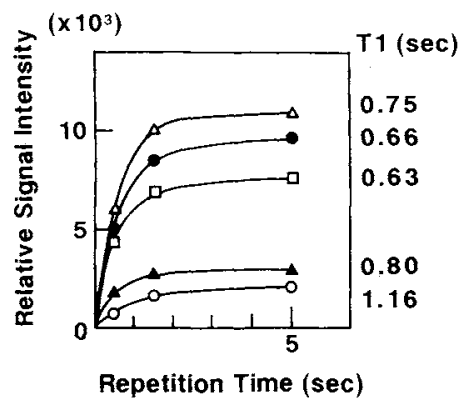

Fig. 6. Measurement of Relaxation Times $\left(T_{1}\right)$ of Free Water by the Progressive Saturation Method using the Signal Intensities Measured with Different Repetition Times

Calculations were done using the results in Fig. 5a; A (O), $\mathrm{B}(\boldsymbol{O}), \mathrm{C}(\triangle), \mathrm{D}(\mathbf{\Delta})$, and $\mathrm{E}(\square)$. The signals in approximately $2 \times 2 \mathrm{~mm}^{2}$ segments in image of ${ }^{1} \mathrm{H}-\mathrm{NMR}$ were sampled and averaged to calculate one relaxation time $\left(T_{1}\right)$. Spin-echo pulse sequences with $36 \mathrm{msec}$ of echo time and 3 different repetition times $(0.5,1.5$, and $5.0 \mathrm{sec})$ were used. tion times than in the inside and top regions (Fig. 5b). Stored materials are reported to restrict the mobility of water in cells, ${ }^{8)}$ so this suggested that the materials stored in the base and edge parts were consumed faster than the top and inside parts.

Changes in the free water distribution in the cotyledon along with growth from 9 days to 23 days are shown in Fig. 7. The intensity corresponding to the amount of the free water increased 23 days after imbibition. According to the changes in relaxation time listed in Table I, an abrupt increase in relaxation time from under $1 \mathrm{sec}$ to $1.5 \mathrm{sec}$ was observed between the 18 th day and the 23th day. Before this the signal of the fatty acids in the ${ }^{13} \mathrm{C}-\mathrm{NMR}$ spectrum had disappeared and the vacuolar inorganic phosphate signal in the ${ }^{31} \mathrm{P}-\mathrm{NMR}$ spectrum had increased.

Stored sucrose was used within 9 days, then triglyceride-fatty-acids were used (Fig. 1b). Finally, stored materials are known to be consumed until 18 days after imbibition from

Table I. Changes in RelaXation Times $\left(T_{1}\right)$ Within the Various Places in Cotyledon during Germination

\begin{tabular}{cccc}
\hline & \multicolumn{3}{c}{ Relaxation time $(\mathrm{sec})$} \\
\cline { 2 - 4 } imbibition & $\mathrm{A}$ & $\mathrm{B}$ & $\mathrm{C}$ \\
\hline 23 & 1.39 & 1.45 & 1.59 \\
18 & 1.16 & 0.75 & 0.66 \\
14 & 1.04 & 0.78 & 0.69 \\
9 & 1.04 & 0.93 & 0.82 \\
\hline
\end{tabular}

The sampling points, A, B and $\mathrm{C}$ are shown in Fig. 5(a).
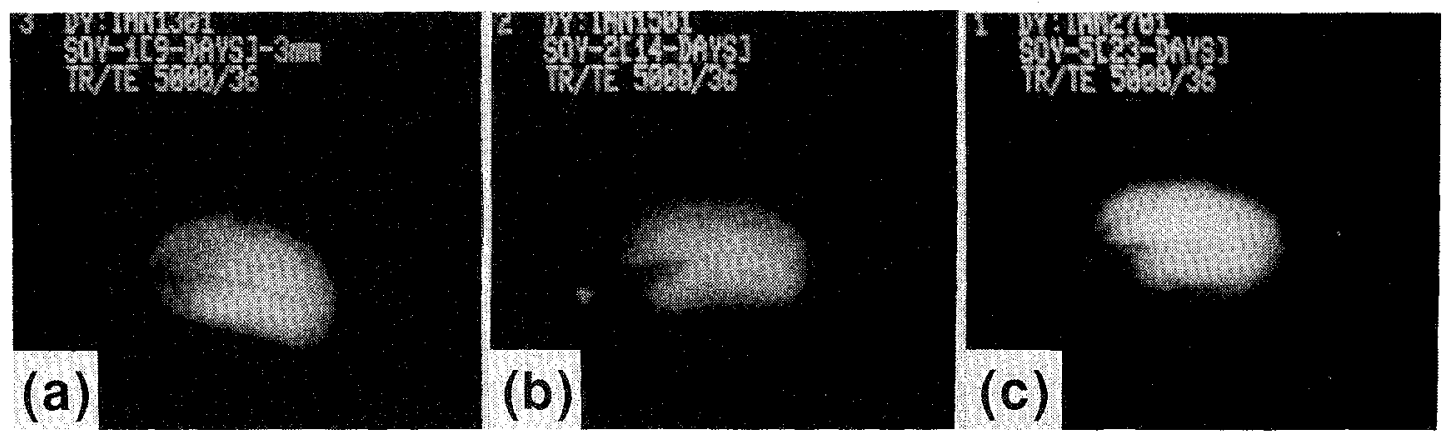

Fig. 7. Distribution Maps of Free Water in Cotyledon at 9 (a), 14 (b) and 23 (c) Days after Imbibition of Water. 

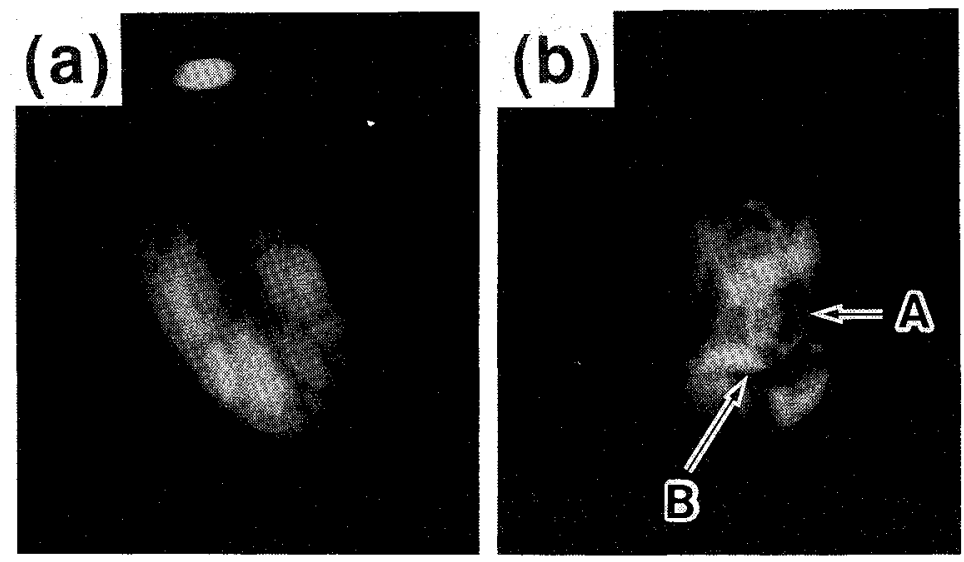

Fig. 8. Distribution Maps of Free Water in a Cotyledon (a) and That Suffered Imbibitional Damage (b) 20 Days after Imbibition.

the ${ }^{13}$ C-NMR spectrum (Fig. 1b). At this time water mobility was restricted but it abruptly increased afterward (Table I). The ${ }^{31}$ P-NMR signal changes indicate that the cells in the cotyledon were vacuolated at this stage because the vacuolar inorganic phosphate was more than $80 \%$ of the phosphorus compounds (Fig. 2b). On the contrary, the inorganic phosphate in cytoplasm and sugar phosphates, which have a close relationship with energy and carbon metabolism, were present in large percentages before 9 days, suggesting the active operation of the cytoplasmic organization. From the findings in this investigation, the cotyledon acted as the source of materials used for the production of energy and compounds required for seedling growth for approximately 18 days after imbibition until the second leaves began to develop. Cotyledons end their role as storage areas and act as independent tissues afterward.

In our previous paper, a soaking effect at germination which was induced by the rapid absorption of water into dry seeds ${ }^{13-16)}$ was ascribed to the physical destruction of cotyledon tissues by the rapid swelling of stored materials such as proteins and saccharides ${ }^{17)}$ upon imbibition. This soaking effect was examined by ${ }^{1} \mathrm{H}-\mathrm{NMR}$ imaging (Fig. 8). Many cracks were observed, which interrupted the supply of water and the consumption of materials. This may prevent the germination of seeds and reduced the activity in surviving plants, resulting in the decline of the yield.

We conclude that the quality of cotyledons influences seedling growth for approximately 3 weeks after sowing, therefore, quality control during seed storage is important in producing high yields in agricultural practice, as described previously. ${ }^{17,18)}$

Acknowledgment. This work was supported in part by a Grant-in-Aid from the Ministry of Agriculture, Forestry and Fisheries of Japan (Bio-Media Program, BMP 89-VI2).

\section{References}

1) A. M. Mayer and A. Poljakoff-Mayber, "The Germination of Seeds," Pergamon Press, Oxford, New York, Tront, Sydney, Paris, Frankfurt, 1982.

2) D. Koller and A. Hadas, in "Encyclopedia of Plant Physiology," Vol. 12B, ed. by O. L. Lange, P. S. Nobel, C. B. Osmond and H. Ziegler, SpringerVerlag, Berlin, Heiderberg, New York, 1982.

3) J. K. M. Roberts, in "The Biochemistry of Plants," Vol. 13, ed. by P. K. Stumph and E. E. Conn, Academic Press, San Diego, New York, Barkeley, Boston, London, Sydney, Tokyo, Tront, 1987, pp. $181-227$.

4) J. K. M. Roberts, in "Modern Methods of Plant Analysis," Vol. 2, ed. by H. F. Linskens and J. F. Jackson, Springer-Verlag, Berlin, Heiderberg, New York, 1986, pp. 43-59.

5) P. A. Bottomley, H. Roger and T. H. Foster, Proc. Natl. Acad. Sci. U.S.A., 83, 87 (1986);

6) G. A. Johnson, J. Brown and P. J. Kramer Natl. Acad. Sci. U.S.A., 84, 2752 (1987). 
7) D. R. Hoagland, "Lecture on the Inorganic Nutrition of Plants," Chronica Botanica Co., Waltham. Massachusetts, 1944.

8) N. Ishida, H. Kano, T. Kobayashi, H. Hamaguchi and T. Yoshida, Agric. Biol. Chem., 51, 301 (1987).

9) N. Ishida, T. Kobayashi, M. Koizumi and H. Kano, Agric. Biol. Chem., 53, 2363 (1989).

10) M. Yoshida, H. Kano, N. Ishida and T. Yoshida, Agric. Biol. Chem., 53, 1395 (1989).

11) L. A. Colnago and P. R. Seidl, J. Agric. Food Chem., 31, 459 (1983).

12) M. Yoshida, S. Morita and Y. Uesugi, J. Pesticide
Sci., 9, 703 (1984).

13) J. P. McCollum, Plant Physiol., 28, 267 (1952).

14) R. L. Obendorf and P. R. Hobbs, Crop Sci., 10, 563 (1970).

15) B. M. Pollock and J. R. Manalo, J. Am. Soc. Hort. Sci., 95, 415 (1970).

16) C. W. Vertucci and A. C. Leopold, Plant Physiol., 75 , 114 (1984).

17) N. Ishida, H. Kano, T. Kobayashi, H. Hamaguchi and T. Yoshida, Agric. Biol. Chem., 52, 2771 (1988).

18) N. Ishida, H. Kano, T. Kobayashi and T. Yoshida, Agric. Biol. Chem., 52, 2777 (1988). 